\title{
The Millenium Ark: How Long a Voyage, How Many Staterooms, How Many Passengers?
}

\author{
Michael Soulé, Michael Gilpin, William Conway, and Tom Foose \\ School of Natural Resources, University of Michigan, Ann Arbor (M.S.); Department of \\ Biology, University of California, La Jolla (M.G.); New York Zoological Society, Bronx (W.C.); \\ Minnesota Zoological Gardens, Apple Valley (T.F.)
}

\begin{abstract}
Barring holocausts, demographic forecasts suggest a "demographic winter" lasting 500-1,000 years and eliminating most habitat for wildlife in the tropics. About 2,000 species of large, terrestrial animals may have to be captively bred if they are to be saved from extinction by the mushrooming human population. Improvements in biotechnology may facilitate the task of protecting these species, but it probably will be decades at least before cryotechnology per se is a viable alternative to captive breeding for most species of endangered wildlife. We suggest that a principle goal of captive breeding be the maintenance of $90 \%$ of the genetic variation in the source (wild) population over a period of 200 years. Tables are provided that permit the estimation of the ultimate minimum size of the captive group, given knowledge of the exponential growth rate of the group, and the number of founders. In most cases, founder groups will have to be above 20 (effective) individuals.
\end{abstract}

Key words: zoos, captive breeding, genetic variation, endangered species, heterozygosity, population growth

\section{INTRODUCTION}

According to the models of the UN [United Nations, 1982] and the World Bank [World Bank, 1984], the world population is likely to level off at around 10 to 12 billion about 100 years from now. The implicit assumptions of these forecasts are (1) that agricultural output continues to increase at current rates, (2) that the climatic and agricultural consequences of $\mathrm{CO}_{2}$ warming, loss of topsoil, and deforestation are insignificant, and (3) that water supplies on a per capita basis can be sustained. These are all unlikely. Thus, famines and other catastrophes may limit the population, especially in Africa, before it approaches these levels. Nevertheless, we can probably expect a near doubling in population size within 100 years.

Received for publication September 17, 1985; accepted October 22, 1985.

(c) 1986 Alan R. Liss, Inc. 
Given the rate of habitat destruction today (with only 4.8 billion people), it is likely that the rate will be higher in the year 2100 . The reasons are, first, that land and firewood are likely to be in short supply for many decades, especially in the tropical, developing countries. These demands will place additional strains on the remaining $50 \%$ of tropical forests. Second, the capacity for regeneration of the renewable resouces will be compromised by increased levels of exploitation as it already has been in fisheries owing to overfishing [Nelson and Soulé, in press], in grasslands owing to overgrazing [Eckholm and Brown, 1977], and in forests owing to extraction and erosion [Myers, 1980].

How long will the human population remain at or near the peak level and when will the human usurpation of wildlands end? That is, what is the duration of the "demographic winter?" Ignoring the obligatory disclaimers about extrapolative speculation, our guess is about 500 or 1,000 years. It is obviously impossible to foresee cultural values and public policy in any nation several centuries from now. Nevertheless, we assume that after achieving zero population growth, it will be very difficult

TABLE 1. A Preliminary Attempt to Predict the Number of Mammalian Species That Will Require Captive Maintenance in the Next 200 Years*

\begin{tabular}{|c|c|c|}
\hline Order & $\begin{array}{l}\text { No. of } \\
\text { recognized } \\
\text { species }\end{array}$ & $\begin{array}{c}\text { No. of vulnerable } \\
\text { species that may require } \\
\text { captive breeding }\end{array}$ \\
\hline Monotremata & 4 & \\
\hline Marsupicarnivora & 123 & 2 \\
\hline Peramelina (bandicoots) & 18 & \\
\hline Paucituberculata (shrew-like) & 7 & \\
\hline Diprotodonta (herbivores) & 101 & \\
\hline Insectivora & 409 & \\
\hline Dermoptera (colugos) & 2 & 2 \\
\hline Chiroptera & $\sim 900$ & 100 \\
\hline Primates & 160 & 160 \\
\hline Edentata (anteaters, sloths) & 25 & 10 \\
\hline Pholidota (pangolins) & 7 & 5 \\
\hline Mysticeta & 10 & 2 \\
\hline Odontoceta (toothed whales) & 65 & 10 \\
\hline \multicolumn{3}{|l|}{ Carnivora } \\
\hline Canidae & 35 & 35 \\
\hline Ursidae & 7 & 2 \\
\hline Felidae & 72 & 60 \\
\hline Others & 193 & 100 \\
\hline Lagomorpha & 53 & $?$ \\
\hline Rodentia & $\sim 1,700$ & 100 \\
\hline Tubulidentata & 1 & 1 \\
\hline Probroscidea & 2 & 2 \\
\hline Hyracoidea & 11 & 5 \\
\hline Sirenia & 4 & 4 \\
\hline Perissodactyla & 15 & 15 \\
\hline Artiodactyla & $\sim 172$ & 100 \\
\hline Total & & 815 \\
\hline
\end{tabular}

*The estimates of "Number of vulnerable species that may require captive breeding" assume the virtual destruction of natural habitats in the tropics, with the exception of northern Australia and scattered nature reserves. It is assumed that none of the nature reserves will be sufficiently large to protect the larger mammals [Frankel and Soulé, 1981]. 
to bring down the population to an optimum level. Only in very disciplined, regimented cultures is the goal of one child per family likely to be achieved. On the other hand, a resolution of the population explosion might occur much sooner as a consequence of famines, epidemics, or a nuclear holocaust.

Even if we assume that the population drops relatively quickly, say in two or three centuries, we cannot be certain that this will result in the abandonment of the lands that, today, are habitat for wildlife, but that tomorrow will be cities, villages and farms. It is unrealistic to assume that peoples will be easily convinced to abandon villages and farms that have become traditional sites of occupation, unless the land is no longer arable. On the other hand, the reconstruction of quasinatural habitats might become a major social goal in the future. People, especially the young, will leave rural areas if there are real or imagined economic incentives, as evidenced by the exodus to cities now occurring in many tropical nations.

There is another problem, as well. Most of the tropical and temperate lands that still support wildlife today, even the forested lands, are hydrologically and agriculturally marginal. Many of these lands will be seriously degraded if they are settled, and their soils eroded, compacted, or turned to brick. So, even if these lands can be relinquished, centuries may pass before they could provide optimum habitat for wildlife.

This brief futuristic preamble seems to support the pessimistic view that contemporary zoological and botanical gardens must be prepared to be stewards of their charges for many centuries or millenia, barring the development of less spaceintensive ways of maintaining viable populations. But even if technological solutions are found for maintaining many species in miniaturized and suspended states, it may be impossible to recapture a true twentienth century ecosystem, with all its complex biotic and functional diversity. The reason is that the large majority of species are smaller plants and animals. These will have been extinct for a long time unless relatively large and well managed fragments of habitat are maintained during the demographic winter [Soulé and Simberloff, 1986].

\section{HOW MANY KINDS?}

How many species will be in the ark? Myers [1984] suggests that we will lose between one-quarter and one-half of all species. Assuming that there are between 10 million and 31 million [Erwin, 1982] species on the planet, we must anticipate losing between 3 million and 16 million species. Of course, the vast majority of these are insects [Raven, 1976; Erwin, 1982].

How many will be vertebrates, especially birds and mammals? A worst case scenario assumes a near total blitzkrieg of national parks and similar reserves in the tropical countries. This is not at all unlikely in the opinion of some [eg, Myers, 1984] with experience in Africa and parts of tropical Asia and Latin America. If this most dreary scenario comes to pass, then we can assume that the larger vertebrates will be the hardest hit. In Table 1 we provide a rough analysis of the number of mammalian species that would be in serious jeopardy. The following groups will all but disappear unless they are captively maintained: primates (160), the large carnivores (ca 100), the perissodactyls (15) and most of the artiodactyls (ca 100). In addition, about 300 species from the other orders will be wiped out. This is about 800 species. We estimate that the same will be true for birds. Locally endemic species in the tropics 
[Terborgh and Winter, 1983] and migratory birds are especially vulnerable because they are entirely dependent for their survival on habitats (islands, tropical forests) with dismal prospects. There will probably also be several hundred species of reptiles and amphibians in need of special protection. Therefore, we must consider that at least 2,000 species of large, terrestrial vertebrates will be among the missing unless there is room in the ark.

During the past 2 years, about $19 \%$ of the world's mammals and about $9 \%$ of all the species of birds have been bred by those zoos reporting to the International Zoo Yearbook (IZY) censuses. The mostly North American collections reporting in the International Species Inventory System (ISIS) contain about 60,000 specimens of mammals and birds (reptiles, amphibians, fishes, and invertebrates are not yet in this system) in 175 reporting collections. Ninety percent of all mammals and almost $\mathbf{7 5 \%}$ of all birds added to these collections last year were bred in captivity, and the numbers of many of the endangered species they hold are steadily increasing.

Between 1973 and 1983, for example, there was a doubling of the numbers of snow leopards (130 to 300). Many other species showed similar increases including Siberian tigers $(400$ to 1,200 ), golden lion tamarins ( 85 to about 400 ), many endangered ungulates such as barasingha (114 to 291), brow-antlered deer (37 to 101), gaur (32 to 83), scimitar-horned oryx (141 to 511), Arabian oryx (75 to 161), addax (142 to 329 ), and dama gazelle (58 to 178 ) and many others.

The ability of zoos to breed most mammals and birds is no longer in doubt, but the ultimate carrying capacity of zoos is far from clear. If zoos are to undertake the long-term maintenance of the increasing numbers of refugee species, organized planning should begin now, and on an international scale. Among the difficult questions that need answers: "Is there enough space in the ark?"

Although there are nearly 540,000 mammals, birds, reptiles, and amphibians in zoos reporting to the American Association of Zoological Parks and Aquaria and the IZY, it is unrealistic to assume that more than half of these spaces can be used for long-term propagation. Analysis of present zoo populations suggests that about 330 mammals could be sustained at a population size of $275 ; 467$ birds, 96 reptiles, and 32 amphibians, each at a population of $300 ; 925$ species in all. These sizes (275 and 300) may be larger than necessary for strictly genetic considerations, and might be reduced eventually. Even the number 925 , however, may be optimistic given the present logistical and collaborative disarray [Conway, in press]. Such calculations are quite arbitrary (for reasons elaborated below), but they suggest the magnitude of the problem, and the level of commitment required.

Within two or three decades, it may be necessary to devote most of the space in zoos to the captive breeding of endangered species. Such a statement might alarm many in the zoo community, until it is realized that most of the species currently held in zoos will be shifted, one by one, from the nonendangered to the endangered category by virtue of habitat destruction. Nevertheless, the message of the preceding paragraphs is that zoos will need help. Current budgets, facilities, and techniques are no match for the gigantic task of conserving the plant's megafauna.

Is help on the way? The ultimate solution, we believe, must come from research in developmental and reproductive biology focused on the preservation and regeneration of viable organisms from zygotes and embryonic cells. Admittedly, cryogenics, like most technological fixes, is no magic solution. Millions of dollars and decades of research have been invested in the development of the techniques for just a single 
species-cattle-and to a lesser extent for horses. So far, the techniques are not transferable to many other species.

On the other hand, there is continuing progress in this field, especially considering where the science was just 20 years ago. Based on the recent successes in bovids, equids, and primates, we consider it likely that traditional captive breeding programs for many species in these groups will be obsolete in a few decades (given reliable refrigeration), and that the vacated space will become available for other taxa. (Even such technological breakthroughs will not obviate the need to maintain some living representatives of most species to serve educational, cultural, recreational and technical-scientific purposes.) In addition, we cannot predict what unforeseen technologies will be developed. We would strongly urge the research community, in and out of zoos, to give high priority to research on cryogenic or other technologies for the long-term preservation of sperm, ova, and embryonic materials, along the lines of the recommendations of the recent FAO/UNEP report on this subject [FAO, 1984].

In the meantime, zoos and similar institutions will have to do their best to maintain relatively large, viable populations of higher vertebrates that are threatened with extinction in their natural habitats. We must therefore determine, as best as we can, the minimum number of individuals in such breeding colonies that will guarantee the maintenance of viability.

\section{HOW MANY OF EACH KIND?}

As has been described elsewhere [Frankel and Soulé, 1981], the number of individuals required for the maintenance of genetic fitness in a population depends on several variables. These are (1) the definition and the criteria for fitness, (2) the intended duration of the program, and (3) the generation time. We must add a fourth variable, one that is only appropriate for breeding programs with a finite lifetimethe maximum tolerable loss of genetic variation. No loss of additive genetic variation should be tolerated in a program of indefinite length. These four variables will be described briefly.

Fitness in the immediate, or short-term, sense concerns individuals. It is the current viability and reproductive success of the individuals in the group. Inbreeding can compromise short-term fitness by producing abnormally high levels of homozygosity for deleterious, recessive genes, the genetic load. There is a large body of evidence [Soulé, 1980; Allendorf and Leary, 1986] suggesting that even very modest decreases in heterozygosity can reduce fitness as estimated by physiological efficiency, growth rates, and developmental (morphological) stability. By trial and error, animal breeders have learned that inbreeding problems (depression) can be avoided if the rate of inbreeding per generation, F, remains below 2\% [Franklin, 1980; Soulé, 1980]. Employing the approximation

$$
\mathrm{F}=\frac{1}{2 \mathrm{~N}_{\mathrm{e}}}
$$

where $\mathrm{N}_{\mathrm{e}}$ is the effective size of the population, the corresponding effective population size is about 25. Franklin [1980], Soulé [1980], and Frankel and Soulé [1981] 
recommended a slightly more conservative short-term maximum rate of inbreeding $(\mathrm{F}=1 \%)$, equivalent to an effective size of about 50 . A $1 \%$ rate of genetic erosion was considered tolerable by these authors because they were assuming that the groups would be released into the wild within a very short time, say 100 years, an interval that now appears optimistic.

Fitness in the long-term or ultimate sense means the capacity of the population to maintain itself indefinitely in its environment. Thus, long-term viability or fitness is variously defined as adaptability (genetic) to environmental change, the maintenance of evolutionary fitness, and population homeostasis. Obviously, the retention of long-term fitness or viability requires the preservation of genetic variation.

How do we go about estimating the time-frame of the ex situ conservation effort for vertebrates? In light of the unpleasant demographic scenario painted above, it would not be unreasonable to plan for a voyage of 1,000 years. An optimist, on the other hand, would argue that applications of molecular biology to the fields of development and reproductive physiology are just entering an "exponential growth phase," and that technologies for storage and regeneration of embryonic cells that are unimaginable today will be available in less than a century. As these technologies come on line, more species can be moved from the space- and resource-intensive "living zoo" to the miniaturized, "suspended zoo." If this scencario is correct, our descendents will be able to replace the millenium ark with a "millenium freezer."

We wish to make it clear that none of us is enamored of the "technological fix" as a solution to major social ills. Technology has never permanently "solved" major human problems such as hunger, poverty, injustice, and warfare. But technology, when applied to specific, technical objectives is very successful, as evidenced by word processors, putting humans in space, and refrigeration.

Regarding the security of frozen or suspended zoos, they are as secure as society itself. There would be redundancy in the holdings, with collections dispersed throughout the world. For those who are nervous about the power failing everywhere at once, the consequences of such a planet-wide catastrophe would be just as serious for zoos as for suspended collections - the pillaging of zoos with all their meat on the hoof, would take no longer than the thawing of all the freezers. In this context, it is not as far-fetched as it sounds to begin planning long-term storage facilities on the back side of the moon.

Another obvious caveat is that a suspended zoo cannot protect the vast majority of smaller organisms that are now threatened with extinction, especially in the tropics. The majority of insect species are undescribed taxonomically [Erwin, 1982] as are a large fraction of neotropical plants [Gentry, 1986]. Whether described or not, most organisms, especially those in the tropics, are small, relatively inconspicuous, and unknown ecologically. Their only human constituency is a handful of biologists; their only refuge is in nature reserves.

Returning to the "how long?" issue, the consensus of the authors is that 200 years is a reasonably conservative temporal horizon. Great works of art have been preserved much longer, even if their collectors and repositories were not. A longer time frame ignores the exponential rate of progress in biological technology. Those who think that 200 years is either too short to too long are free to adjust their programs accordingly. Indeed, conservationists of the 21 st Century will have the option to modify their time horizons and to make compensatory changes in effective population sizes, if they conclude that such action is necessary. Fortunately, decisions 
made during the initiation phases about effective size are, to some extent, revocable in the first few decades.

Because ultimate or long-term viability or adaptive potential depends on the store of genetic variability, it is desirable to retain as much genetic variability as possible. Ignoring the input of genetic variability from mutation (which in any case will probably be less than the loss when the effective population size is less than a few hundred), we believe that a $90 \%$ criterion is reasonable and realistic. That is, the goal should be to preserve at least $90 \%$ of the genetic variability that existed in the source population over the next 200 years. Any such criterion is clearly arbitrary. Nevertheless, it was the consensus that the $90 \%$ threshold represents, intuitively, the zone between a potentially damaging and a tolerable loss of heterozygosity.

It is prudent to have as many founder individuals as possible. There are two principal reasons for this. First, the more founders, the more genetic variability. Even though a pair of individuals will contain, on average, $75 \%$ of the genetic variation or heterozygosity for quantitative traits in the source population (assuming no dominance and epistasis), rare alleles will not survive such a small bottleneck in the number of founders [Allendorf, 1986; Fuerst et al, 1986]. The ratio of genetic variation in the founders compared to the source population approaches 1.0 asymptotically in the range of 25-30 individuals [Gilpin and Soulé, in preparation].

Second, the more founders, the sooner the group will reach the target population size or $\mathrm{N}_{\mathrm{K}}$. The rate of approach to $\mathrm{N}_{\mathrm{K}}$ depends on the population growth rate [Nei et al, 1975]. When the growth rate is low, the loss of genetic variation from genetic drift can be high in the early generations. The optimum situation, therefore, is to have a large number of founders, say more than 20 , and to achieve $N_{K}$ very quickly. Parenthetically, the potential for interaction and gene flow between captive groups and wild populations of a species is important. Where survival of a wild population is possible, the benefits of coordinated management should not be dismissed by purists on either side.

Generation time is critical because reproduction is the only point in the life history when there is loss of alleles or genetic variation. Consequently, the longer the generation time, the fewer opportunities there will be for the loss of genetic variation. For example, there will only be eight such opportunities in 200 years when the generation time is 25 years.

Our principal conclusions are summarized in Tables $2-8$. The methodology is presented elsewhere [Gilpin and Soulé, in preparation]. Each of the tables was generated by using a unique value for the intrinsic rate of increase per generation (population growth) for the group, from the time of founding until it reached $\mathrm{N}_{\mathrm{K}}$. These growth rates span the range that is typical of zoo species. The other assumptions used in the calculations include (1) a 200-year program, (2) the retention of $90 \%$ of the genetic variation for quantitative traits, and (3) random breeding within the group, as well as (4) non-overlapping generations, (5) an equal sex ratio, and (6) Poissondistributed family size. The absence of values in the upper parts of some of the tables indicates that more than $10 \%$ of the genetic variation is lost even if $\mathrm{N}_{\mathrm{K}}$ is infinite. The value 999 indicates that $\mathrm{N}_{\mathrm{K}}$ lies between 1,000 and 10,000.

Some remarks about these results are in order. First, note that the founder effective size must always be six or above if the $90 \%$ criterion is to be met. With fewer than six founders, the group will lose more than $10 \%$ or more of the genetic variation existing in the source population as soon as it reproduces. 
TABLE 2. Carrying Capacities Necessary for the Retention of $90 \%$ of the Initial Genetic Variance*

\begin{tabular}{lllllllllllll}
\hline $\begin{array}{l}\text { No. of } \\
\text { founders }\end{array}$ & 1 & 2 & 4 & 6 & 8 & 10 & 15 & 20 & 25 & 30 & 50 \\
\hline 16 & - & - & - & - & - & - & - & - & - & - & - \\
18 & - & - & - & - & - & - & - & - & - & - & 20 \\
20 & - & - & - & - & - & - & - & - & - & - & 19 \\
22 & - & - & - & - & - & - & - & - & - & - & 19 \\
24 & - & - & - & - & - & - & - & - & - & - & 18 \\
26 & - & - & - & - & - & - & - & - & - & 31 & 18 \\
28 & - & - & - & - & - & - & - & - & - & 29 & 17 \\
30 & - & - & - & - & - & - & - & - & - & 29 & 17 \\
32 & - & - & - & - & - & - & - & - & - & 29 & 17 \\
34 & - & - & - & - & - & - & - & - & 40 & 28 & 17 \\
36 & - & - & - & - & - & - & - & - & 39 & 28 & 17 \\
38 & - & - & - & - & - & - & - & - & 39 & 28 & 17 \\
40 & - & - & - & - & - & - & - & 53 & 39 & 28 & 16 \\
\hline
\end{tabular}

*The exponential growth rate per generation is 0.05 .

TABLE 3. Carrying Capacities Necessary for the Retention of $90 \%$ of the Initial Genetic Variance*

\begin{tabular}{|c|c|c|c|c|c|c|c|c|c|c|}
\hline \multirow{2}{*}{$\begin{array}{l}\text { No. of } \\
\text { founders }\end{array}$} & \multicolumn{10}{|c|}{ Length of generation (years) } \\
\hline & 1 & 2 & 4 & 6 & 8 & 10 & 15 & 20 & 25 & 30 \\
\hline 6 & - & - & - & - & - & - & - & - & - & - \\
\hline 8 & - & - & - & - & - & - & - & - & - & - \\
\hline 10 & - & - & - & - & - & - & - & - & - & - \\
\hline 12 & - & - & - & - & - & - & - & - & - & - \\
\hline 14 & - & - & - & - & - & - & - & - & - & - \\
\hline 16 & - & - & - & - & - & - & - & - & - & - \\
\hline 18 & - & - & - & - & - & - & - & - & - & - \\
\hline 20 & - & - & - & - & - & - & - & - & - & - \\
\hline 22 & - & - & - & - & - & - & - & - & - & - \\
\hline 24 & - & - & - & - & - & - & - & - & - & 32 \\
\hline 26 & - & - & - & - & - & - & - & - & - & 30 \\
\hline 28 & - & - & - & - & - & - & - & - & - & 29 \\
\hline 30 & - & - & - & - & - & - & - & - & 43 & 29 \\
\hline
\end{tabular}

${ }^{*}$ The exponential growth rate per generation is .1 .

Second, $\mathrm{N}_{\mathrm{K}}$ is very sensitive to $\mathrm{N}_{\mathrm{F}}$, the number of founders, although above $\mathrm{N}_{\mathrm{F}}$ s of about 25 , the effect diminishes very rapidly. A very great decrease in $\mathrm{N}_{K}$ can be achieved by doubling $\mathrm{N}_{\mathrm{F}}$, especially if it is combined with artificially delayed reproduction. As shown in Table 5, for example, a decrease in $N_{K}$ from 617 to 124 is achieved by an increase in $\mathrm{N}_{\mathrm{F}}$ from 12 to 24 while increasing the generation time from 6 to 10 years.

Third, the tables contain regions of biological impossibility. For example, Table 7 , which corresponds to the intrinsic rate of increase of small rodents that produce several litters of about five offspring per year, shows generation lengths that are unattainable in such species. It should be noted also that the goal of $90 \%$ retention of genetic variance for 200 years is virtually unattainable at generation growth rates of 
TABLE 4. Carrying Capacities Necessary for the Retention of $90 \%$ of the Initial Genetic Variance*

\begin{tabular}{|c|c|c|c|c|c|c|c|c|c|c|}
\hline \multirow{2}{*}{$\begin{array}{l}\text { No. of } \\
\text { founders }\end{array}$} & \multicolumn{10}{|c|}{ Length of generation (years) } \\
\hline & 1 & 2 & 4 & 6 & 8 & 10 & 15 & 20 & 25 & 30 \\
\hline 6 & - & - & - & - & - & - & - & - & - & - \\
\hline 8 & - & - & - & - & - & - & - & - & - & - \\
\hline 10 & - & - & - & - & - & - & - & - & - & - \\
\hline 12 & - & - & - & - & - & - & - & - & - & - \\
\hline 14 & - & - & - & - & - & - & - & - & - & - \\
\hline 16 & - & - & - & - & - & - & - & - & - & - \\
\hline 18 & - & - & - & - & - & - & - & - & - & 39 \\
\hline 20 & - & - & - & - & - & - & - & 112 & 60 & 34 \\
\hline 22 & - & 999 & 999 & 999 & 642 & 384 & 137 & 77 & 50 & 32 \\
\hline 24 & 999 & 999 & 999 & 582 & 362 & 243 & 106 & 66 & 45 & 30 \\
\hline 26 & 999 & 999 & 768 & 424 & 274 & 192 & 92 & 60 & 43 & 30 \\
\hline 28 & 999 & 999 & 617 & 348 & 234 & 164 & 84 & 56 & 42 & 29 \\
\hline 30 & 999 & 999 & 538 & 309 & 208 & 148 & 79 & 54 & 40 & 29 \\
\hline
\end{tabular}

*The exponential growth rate per generation is .3.

TABLE 5. Carrying Capacities Necessary for the Retention of $90 \%$ of the Initial Genetic Variance*

\begin{tabular}{lcccccccccc}
\hline \multirow{2}{*}{$\begin{array}{l}\text { No. of } \\
\text { founders }\end{array}$} & $\mathbf{1 0}$ & $\mathbf{1 0}$ & \multicolumn{10}{c}{ Length of generation (years) } \\
\cline { 2 - 11 } & 1 & 4 & 6 & 8 & 10 & 15 & 20 & 25 & 30 \\
\hline 6 & - & - & - & - & - & - & - & - & - & - \\
8 & - & - & - & - & - & - & - & - & - & - \\
10 & - & - & - & - & - & - & - & - & - & - \\
12 & - & - & - & - & - & - & - & - & - & - \\
14 & - & - & - & - & - & - & - & - & 157 & 55 \\
16 & 999 & 999 & 999 & 936 & 617 & 424 & 188 & 110 & 70 & 39 \\
18 & 999 & 999 & 882 & 517 & 348 & 253 & 124 & 80 & 55 & 35 \\
20 & 999 & 999 & 655 & 384 & 269 & 196 & 102 & 69 & 49 & 32 \\
22 & 999 & 999 & 538 & 321 & 225 & 167 & 90 & 62 & 45 & 31 \\
24 & 999 & 999 & 468 & 285 & 200 & 148 & 84 & 59 & 43 & 30 \\
26 & 999 & 936 & 432 & 258 & 184 & 137 & 79 & 55 & 42 & 30 \\
28 & 999 & 865 & 399 & 243 & 174 & 129 & 76 & 54 & 41 & 29 \\
30 & 999 & 815 & 376 & 229 & 164 & 124 & 73 & 52 & 40 & 29 \\
\hline
\end{tabular}

*The exponential growth rate per generation is .5 .

$<0.1$, unless both generation length and $\mathrm{N}_{\mathrm{F}}$ are $>25$. For example, Table 8 tabulates the values for slowly reproducing animals (exponential growth rate per generation = 0.05 ). Very large numbers of founders are required to meet the $90 \%$ criterion. Actual growth rates in zoos are often far below those in the wild, for a variety of reasons. Examples of some actual exponential growth rates per year in captive groups might be useful: okapi, 0.1; lion-tailed macaque, 0.05; Siberian tiger, 0.09 (rate is artificially low); Przewalski's horse, 0.10; gaur, 0.11; golden lion tamarin, 0.22.

Figure 1 illustrates a small sample of the tabulated results from Table 5. Curve A was generated with $\mathrm{N}_{F}=10$; curve $B$ with $\mathrm{N}_{\mathrm{F}}=20$; curve $C$ with $\mathrm{N}_{F}=\mathrm{N}_{K}$. The latter assumption is very unrealistic, but note the small effect on $N_{K}$ of increasing the founder size above 20 . 
TABLE 6. Carrying Capacities Necessary for the Retention of $90 \%$ of the Initial Genetic Variance*

\begin{tabular}{lccccccccccc}
\hline \multirow{2}{*}{$\begin{array}{l}\text { No. of } \\
\text { founders }\end{array}$} & \multicolumn{10}{c}{} & \multicolumn{10}{c}{ Length of generation (years) } \\
\cline { 2 - 13 } & 1 & 2 & 4 & 6 & 8 & 10 & 15 & 20 & 25 & 30 \\
\hline 6 & - & - & - & - & - & - & - & - & - & - \\
8 & - & - & - & - & - & - & - & - & - & - \\
10 & - & - & 999 & 999 & 999 & 999 & 682 & 392 & 225 & 102 \\
12 & 999 & 999 & 999 & 617 & 432 & 321 & 174 & 117 & 80 & 49 \\
14 & 999 & 999 & 655 & 399 & 285 & 216 & 122 & 85 & 61 & 40 \\
16 & 999 & 999 & 517 & 321 & 229 & 174 & 102 & 71 & 53 & 35 \\
18 & 999 & 955 & 450 & 280 & 200 & 154 & 90 & 65 & 48 & 33 \\
20 & 999 & 848 & 399 & 253 & 184 & 140 & 84 & 60 & 45 & 32 \\
22 & 999 & 783 & 376 & 234 & 170 & 132 & 79 & 57 & 43 & 31 \\
24 & 999 & 738 & 355 & 220 & 161 & 124 & 76 & 55 & 42 & 30 \\
26 & 999 & 709 & 334 & 212 & 154 & 119 & 73 & 53 & 42 & 30 \\
28 & 999 & 682 & 321 & 204 & 151 & 117 & 71 & 52 & 41 & 29 \\
30 & 999 & 655 & 315 & 200 & 145 & 115 & 70 & 52 & 40 & 29 \\
\hline
\end{tabular}

*The exponential growth rate per generation is 1 .

TABLE 7. Carrying Capacities Necessary for the Retention of $90 \%$ of the Initial Genetic Variance*

\begin{tabular}{lccccccccccc}
\hline \multirow{2}{*}{$\begin{array}{l}\text { No. of } \\
\text { founders }\end{array}$} & \multicolumn{10}{c}{ Length of generation (years) } \\
\cline { 2 - 11 } & 1 & 2 & 4 & 6 & 8 & 10 & 15 & 20 & 25 & 30 \\
\hline 6 & - & - & - & - & - & - & - & - & - & - \\
8 & 999 & 999 & 999 & 723 & 527 & 407 & 239 & 167 & 122 & 80 \\
10 & 999 & 999 & 617 & 392 & 291 & 225 & 134 & 98 & 73 & 49 \\
12 & 999 & 993 & 477 & 303 & 225 & 174 & 106 & 77 & 59 & 40 \\
14 & 999 & 848 & 407 & 264 & 192 & 151 & 92 & 67 & 52 & 37 \\
16 & 999 & 768 & 369 & 239 & 177 & 140 & 85 & 62 & 48 & 34 \\
18 & 999 & 709 & 348 & 225 & 167 & 129 & 79 & 60 & 46 & 33 \\
20 & 999 & 682 & 328 & 212 & 157 & 124 & 76 & 57 & 44 & 32 \\
22 & 999 & 655 & 315 & 204 & 151 & 119 & 74 & 55 & 43 & 31 \\
24 & 999 & 630 & 309 & 200 & 148 & 115 & 73 & 54 & 42 & 30 \\
26 & 999 & 617 & 297 & 192 & 143 & 112 & 71 & 53 & 42 & 30 \\
28 & 999 & 605 & 291 & 188 & 140 & 110 & 70 & 52 & 41 & 29 \\
30 & 999 & 593 & 285 & 184 & 137 & 108 & 69 & 52 & 40 & 29 \\
\hline
\end{tabular}

*The exponential growth rate per generation is 3 .

Our model does not take into account the generation of genetic variation by mutation. Above some theoretical equilibrium size, a population will gain genetic variance by mutation faster than it loses it by genetic drift [Franklin, 1980]. Existing data do not permit an estimate of such an equilibrium. (Actually, there are as many equilibria as there are categories of phenotypic traits for which mutation rates can be measured.) Nevertheless, we are in agreement that the marginal genetic advantage of an effective size of 500 versus 250 is probably insignificant. Because space and facilities will continue to be limiting resources for zoos in the foreseeable future, we believe that the maintenance of more than 200 to 300 effective individuals of a given species is a profligate use of precious resources. For example, one popular species 
TABLE 8. Carrying Capacities Necessary for the Retention of $90 \%$ of the Initial Genetic Variance*

\begin{tabular}{lrlllllllllr}
\hline \multirow{2}{*}{$\begin{array}{l}\text { No. of } \\
\text { founders }\end{array}$} & \multicolumn{10}{c}{ Length of generation (years) } \\
\cline { 2 - 11 } & 1 & 2 & 4 & 6 & 8 & 10 & 15 & 20 & 25 & 30 \\
\hline 6 & - & - & - & 999 & 999 & 999 & 999 & 999 & 999 & 738 \\
8 & 999 & 999 & 831 & 527 & 392 & 303 & 184 & 134 & 100 & 67 \\
10 & 999 & 999 & 538 & 341 & 253 & 200 & 122 & 89 & 67 & 47 \\
12 & 999 & 899 & 432 & 280 & 208 & 164 & 100 & 73 & 56 & 40 \\
14 & 999 & 783 & 384 & 248 & 184 & 145 & 89 & 66 & 52 & 37 \\
16 & 999 & 723 & 355 & 229 & 170 & 134 & 82 & 62 & 48 & 34 \\
18 & 999 & 682 & 334 & 216 & 161 & 127 & 79 & 60 & 46 & 33 \\
20 & 999 & 655 & 321 & 208 & 154 & 119 & 76 & 57 & 44 & 32 \\
22 & 999 & 630 & 309 & 200 & 148 & 117 & 74 & 55 & 43 & 31 \\
24 & 999 & 617 & 303 & 196 & 143 & 115 & 73 & 54 & 42 & 30 \\
26 & 999 & 593 & 291 & 188 & 143 & 112 & 71 & 53 & 42 & 30 \\
28 & 999 & 582 & 285 & 184 & 140 & 110 & 70 & 52 & 41 & 29 \\
30 & 999 & 582 & 285 & 184 & 137 & 108 & 69 & 52 & 40 & 29 \\
\hline
\end{tabular}

*The exponential growth rate per generation is 5 .

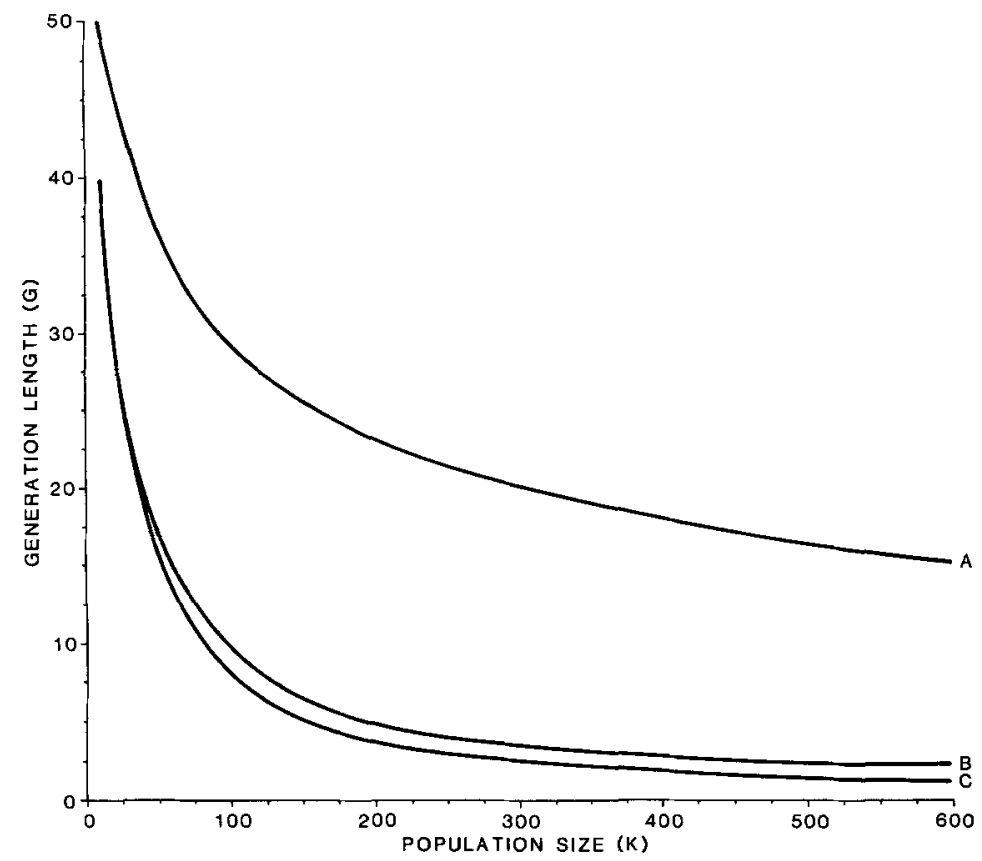

Fig. 1. Combinations of ultimate effective population sizes and generation lengths in years required to maintain $90 \%$ of the genetic variation in the source population. Curve A, founder size of 10; curve B, founder size of 20 ; curve $C$, founder size equals ultimate size. 
(such as tigers) could monopolize much of the space available for large cats. Parenthetically, it is often pointed out that the census number can be significantly reduced by any manipulations that tend to equalize the reproductive output of families.

A certain amount of subdivision will often be desirable, as discussed by Foose et al [1986]. For large animals, the unit of subdivision may often be all the zoos on a continent. Therefore, the values in the tables could represent the target sizes for either the European or the North American subpopulation, though a strict application of this principle would reduce by half the number of species that could be maintained.

\section{CONCLUSIONS}

We have considered the questions "how long, how many staterooms, and how many passengers?" as a cryptic way of asking

1. How long will it be before habitat for wildlife begins to increase rather than decrease?

2. How many species of terrestrial vertebrates will require captive maintenance and propagation?

3. What population sizes are necessary to prevent the decay of fitness and genetic variation in captively bred species?

To the first question, our answer is a millenium, plus or minus 500 years, barring human catastrophes. With regard to captive breeding, however, we qualify this: Assuming that our institutions, and, with them biological technology, survive, a planning horizon of 200 years appears sufficient. By this time, in all likelihood, entirely new technologies for maintaining and regenerating species in miniaturized and suspended states will have been developed.

To the second question, our answer is about 2,000 species of vertebrates (excluding fish), probably plus or minus 500. The captive breeding of so many species will saturate the available space and resources, but, hopefully, advances in cryogenics and similar technologies will obviate the need to maintain all of these at one time as living organisms.

To the third question, the answer is more complex. Our approach is to assume that a reasonable goal is to retain at least $90 \%$ of the genetic variance in the founder group for the interval of two centuries. (Considering such a finite period of time permits much more concrete and tailored answers to the question.) The actual target number is found to depend on the effective size of the founder group, the rate of growth of the population in captivity, and the generation time. The results are tabulated for a range of parameter values.

Even with the highest rates of population growth, the effective size of the founder group must be six or more, assuming that $90 \%$ of the genetic variation in the source populations is to be conserved. Larger founder sizes allow substantial decreases in $\mathrm{N}_{\mathrm{K}}$. This should not be construed, however, to mean that hope should be abandoned if such founder sizes are impractical. The goal of $90 \%$ retention is arbitrary, but it was the consensus that it intuitively represented the zone between a potentially damaging and a tolerable loss of heterozygosity. With careful manage- 
ment, the viability of a captive group should be sustainable, even with fewer founders, and even if the $90 \%$ goal is not attainable.

Animals with very long generation times can be maintained with relatively few individuals. For example, an effective size of only about 40 need be kept if the generation time is 25 years. On the other hand, such small populations may be vulnerable to the misfortunes and vagaries of disease, accidents, and occasional breakdowns in curatorial vigilance. Though zoos, to a large extent, are able to buffer the random variation in their environments and in the demographics of their captive groups, formal captive breeding management plans should estimate the frequencies, probabilities, and genetic consequences of such stochastic perturbations.

\section{REFERENCES}

Allendorf, F.W.; Leary, R.F. Heterozygosity and fitness in natural populations of animals, pp. 57 76 in CONSERVATION BIOLOGY: SCIENCE OF DIVERSITY. M.E. Soulé, ed. Sunderland, MA, Sinauer Associates, 1986.

Allendorf, F. Genetic drift and the loss of alleles versus heterozygosity. ZOO BIOLOGY 5:181$190,1986$.

Conway, W. The practical difficulties and financial implications of endangered species breeding programs. INTERNATIONAL ZOO YEARBOOK, in press.

Eckholm, E.; Brown, L.R. SPREADING DESERTS-THE HAND OF MAN. Washington, DC, Worldwatch Institute, 1977.

Erwin, T.L. Tropical forests: Their richness in Coleoptera and other arthropod species. THE COLEOPTERA BULLETIN 36:74-75, 1982.

FAO. Cryogenic storage of germplasm and molecular engineering. FAO ANIMAL PRODUCTION AND HEALTH PAPER NO. 44/2. Rome 1984.

Foose, T.J.; Lande, R.; Flesness, N.R.; Rabb, G.; Read, B. Propagation plans. ZOO BIOLOGY 5:139-146, 1986.

Frankel, O.H.; Soulé, M.E. CONSERVATION AND EVOLUTION. Cambridge, Cambridge University Press, 1981.

Franklin, I.R. Evolutionary change in small populations, pp. 135-149 in CONSERVATION BIOLOGY: AN EVOLUTIONARY-ECOLOGICAL PERSPECTIVE, M.E. Soulé; B.A. Wilcox, eds. Sunderland, MA, Sinauer Associates, 1980.

Gentry, A. Endemism in tropical versus temperate plant communities, pp. 153-181 in CONSERVATION BIOLOGY: SCIENCE OF DIVERSITY, M.E. Soulé, ed., Sunderland, MA, Sinauer Associates, 1986.
Myers, N. CONVERSION OF TROPICAL MOIST FORESTS. Washington, DC, National Academy of Sciences, 1980.

Myers, N. Genetic resources in jeopardy. AMBIO 13:171-174, 1984.

Nei, M.; Maruyama, T.; Chakraborty, T. The bottleneck effect and genetic variability in populations. EVOLUTION 29:1-10, 1975.

Nelson, K.; Soulé, M.E. Genetical conservation of exploited fishes, in CONSERVATION GENETICS AND ITS APPLICATIONS TO FISHERIES MANAGEMENT. W. Ryman, F. Utter, eds. in press.

Raven, P.H. Ethics and attitudes, pp. 155-179 in CONSERVATION OF THREATENED PLANTS. J.B. Simmons et al, eds. New York, Plenum Press, 1976.

Soulé, M.E. Thresholds for survival: Maintaining fitness and evolutionary potential, pp. 151-169 in CONSERVATION BIOLOGY: AN EVOLUTIONARY-ECOLOGICAL PERSPECTIVE. M.E. Soulé, B.A. Wilcox, eds. Sunderland, MA, Sinauer Associates, 1980.

Soulé, M.E.; Simberloff, D.S. What do genetics and ecology tell us about the design of nature reserves? BIOLOGICAL CONSERVATION 35:19-40, 1986.

Terborgh, J.; Winter, B. A method for siting parks and reserves with special reference to Colombia and Ecuador. BIOLOGICAL CONSERVATION 27:45-58, 1983.

United Nations Department of International Economic and Social Affairs. Long-range global populations projections. POPULATION BULLETIN No. 14, 1982.

World Bank. WORLD DEVELOPMENT REPORT. Washington, DC, 1984. 